УДК 330.12

DOI: $10.14451 / 1.198 .143$

ГРНТИ 06.56.45

\title{
ОСОБЕННОСТИ РАЗВИТИЯ СОВРЕМЕННОГО СЕКТОРА ГОСУДАРСТВЕННЫХ УСЛУГ В УСЛОВИЯХ СМЕШАННОЙ ЭКОНОМИКИ
}

\author{
(c) 2021 Санчес Родригес Виктор \\ аспирант кафедры Экономической теории и менеджмента \\ Московский педагогический государственный университет, Россия, Москва \\ E-mail: mariovictorsanchez2017@gmail.com
}

(c) 2021 Лихачев Михаил Олегович

доктор экономических наук, доцент, профессор кафедры Экономической теории и менеджмента

Московский педагогический государственный университет, Россия, Москва

Главный научный сотрудник Центр научно-информационных исследований по науке, образованию и технологиям

Институт научной информации по общественным наукам (ИНИОН) РАН, Россия, Москва

E-mail: olegmix71@mail.ru

В статье рассматриваются специфические характеристики продукта, создаваемого современным сектором государственных услуг и связанные с этим особенности функционирования этого сектора, а также та особая роль, которую сектор государственных услуг играет в развитии смешанной экономической системы на современном этапе экономической трансформации и глобализации экономических процессов.

Ключевые слова: государственный сектор, услуги, смешанная экономика, общественные блага, рынок государственных услуг, конкуренция, монополия

Экономическое развитие в современной смешанной экономики во многом определяется эффективностью функционирования государственного сектора и, в частности, системы предоставления государственных услуг. В настоящее время государственные услуги стали неотъемлемым компонентом самых разнообразных бизнес-процессов, протекающих во всех сферах экономической жизни, а также важным объектом внимания со стороны многочисленных институтов гражданского общества [1]. Перед современной экономикой и обществом стоит задача превращение сектора государственных услуг из аморфного конгломерата, объединяющего разнообразные сферы деятельности государственных органов в единую, слаженную систему, которая способна эффективно удовлетворять растущие потребности общества в самых разнообразных государственных услугах [5]. В современных условиях первоочередную роль в этом процессе играет применение информационных технологий. Поэтому одной из главных задач развития современной системы предоставления государственных услуг является создание информационно-технологической инфраструктуры, которая способна обеспечить необходимый для современного общества уровень результативности и эффективности в деятельности органов государственной власти как на центральном, так и на местных уровнях [4].

Особое значение эти процессы приобретают в смешанной экономической системе, где государственным структурам приходится взаимодействовать с субъектами частного сектора, в рамках которого доминируют такие нетипичные для государственного сектора стимулы как конкуренция и стремление к получению прибыли. Согласование этих частных интересов с интересами государственных структур, ориентированных на достижение общего блага и повышения уровня общественного благосостояния, создает дополнительные сложности и проблемы для функционирования сектора государственных услуг в современных условиях.

Еще одной важной проблемой является согласование целей и интересов внутри самих государственных структур между различными организациями и уровнями государственной власти и управления [2]. Вся совокупность этих проблем требует углубленного исследования и, прежде всего, теоретического анализа природы государственных услуг как части общественного 
продукта, их специфических отличий от рыночных товаров и услуг и, связанной с этим, специфики процессов формирования спроса и предложения государственных услуг как результата развития общественных потребностей и формирования эффективной системы общественного выбора.

Структурные характеристики продукции сектора государственных услуг

Основные структурные характеристики продукта государственного сектора заключаются в том, что это преимущественно сервисный продукт. В основном государственный сектор предоставляет услуги, а не товары. Поэтому в этой сфере возникают все специфические проблемы, характерные для сферы услуг: нематериальность, которая затрудняет оценку; неотделимость субъекта, оказания услуги, которая ограничивает масштаб операций; неоднородность, которая означает, что качество услуги трудно гарантировать [11]. Кроме того, услуги государственного сектора часто связаны с неравноправными отношениями между поставщиками и получателями услуг. Оценка потребителем качества услуг, как правило, осуществляется постфактум и по косвенным результатам. Это создает необходимость создания системы дополнительного общественного контроля, которая, с одной стороны, позволяет поддерживать качество услуг в государственном секторе, но, с другой стороны, создает дополнительные транзакционные издержки.

Государственные услуги часто содержат элементы того, что экономисты рассматривают в качестве «общественные блага». Эти блага потребляются совместно, то есть не являются конкурентными в потреблении, так что потребление одних субъектов не ограничивает потребление других. Кроме того, они неисключаемы, то есть невозможно исключать из числа потребителей тех, кто их не оплачивает. Однако многие общественные услуги не являются строго общественными благами, хотя и обладают некоторыми их характеристиками. Если та или иная государственная услуга является по своей природе неисключаемой, поставщики коммунальных услуг сталкиваются с классической проблемой «безбилетника». Институциональная теория предполагает, что индивидуалистический корыстный интерес препятствует добровольному участию экономических субъектов в оплате необходимых для них общедоступных благ и создает необходимость использования косвенно-принудительного финансирования через государственную систему налогообложения [7].

Основной организационной характеристикой процесса предоставления общественных услуг являются то, что организации государственного сектора в конечном итоге несут политическую ответственность за конечные результаты своей деятельности. И хотя, непосредственное предоставление государственных услуг может быть функцией государственного или частного агентства, ответственность в конечном итоге лежит на тех, кто руководит соответствующими государственными структурами. Все их действия могут подвергнуться тщательной проверке со стороны вышестоящих инстанций и/или представителей общественности или их политических представителей, что невозможно в сфере частного предпринимательства. Последствия этой характеристики заключаются в том, что организации в государственном секторе осторожны, подчиняются строгим правилам и в силу этого относительно негибки. Даже эксперименты по привлечению частных подрядчиков, агентств и полугосударственных органов способны разорвать эту политическую связь [8].

Еще одной особенностью государственного сектора является развитие нового стиля государственного управления. Государственные администраторы все больше рассматриваются в качестве менеджеров, которых поощряют брать на себя ответственность за предоставление государственных услуг. Практическое профессиональное управление, четкие стандарты работы, стили и практики частного сектора, такие как, экономное использование ресурсов - все это все больше внедряется в сферу повседневной деятельности государственных структур. Таким образом, хотя многие услуги принципиально не изменились, произошли радикальные изменения в организации их предоставления. Во многих случаях реформа государственного сектора усилила требования к качеству предоставления государственных услуг и обозначила более явные параллели с деятельностью в частном секторе [12].

Однако важнейшей отличительной особенностью сектора государственных услуг остается их преимущественно некоммерческий характер. Организация государственного сектора об- 
ладает многими характеристиками, присущими частному некоммерческому сектору. Среди благотворительных, трастовых, правозащитных и медицинских организаций основной целью организации также является не получение прибыли, хотя торговая деятельность вполне может приносить прибыль, ее обычно называют «излишком». Отличие заключается в том, что он будет использован для оказания услуги в следующий период, а не для распределения между собственниками, как это происходит в коммерческих организациях.

Особенности «рынка» государственных услуг

Сфера деятельности государственного сектора чрезвычайно разнообразна с точки зрения населения - потенциальных потребителей государственных услуг, его структуры, и динамики потребностей. Все представители всех групп населения так или иначе потребляют услуги государственного сектора. Однако объединяющей характеристикой таких потребителей является то, что все они являются гражданами. Как граждане люди определяют себя с точки зрения права, долга и идентичности. Гражданство также является эгалитарным понятием, предполагающим равенство обращения со стороны представителей государства независимо от ранга или состояния. Эта идея подкрепляется тем фактом, что многие государственные услуги бесплатны в момент предоставления, а связь между использованием и участием в их финансировании через налогообложение длительная и незначительная.

Специфичность рынка государственных услуг проявляется прежде всего в особых условиях конкуренции на этом рынке. Услуги государственного сектора предоставляются в широком диапазоне конкурентных сфер, начиная от законодательно определенных монополий и кончая эффективной конкуренцией, близкой к идеальной модели совершенной конкуренции. Многие государственные агентства предлагают услуги на нескольких видах конкурентных рынков, имея монополию на некоторых, но не имея защиты на других [9].

Несмотря на широкий диапазон конкуренции, популярный имидж и публичная риторика, окружающие общественные услуги, подчеркивают привилегированный характер рыночной ситуации. В результате рынки общественных услуг на обоих концах конкурентного спектра часто жестко регулируются и контролируются. Кроме того, поставщики государственных услуг часто оказываются перед угрозой приватизации [6]. Даже когда не существует реальной конкуренции, организации реорганизуются, чтобы напоминать создать квазирынки, имитирующие конкуренцию как между отдельными организациями - ростовщиками государственных услуг, так и внутри этих организаций между отдельными подразделениями [10].

Спрос на государственные услуги также имеет специфическую природу. Он опосредован доминирующей политической культурой. Одна из главных особенностей заключается в том, что спрос на государственные услуги может проявляться в качестве требований общественности к государственным структурам, отражаться в предвыборных платформах политических партий и общественных организаций. С другой стороны, в определённых ситуациях спрос на целый ряд государственных услуг создается самими государственными органами путем введения соответствующих норм и правил, которые граждане должны выполнять. Это существенно отличает характер спроса на государственные услуги от спроса, формирующегося на рынках частных товаров и услуг.

Направление совершенствования функционирования рынка государственных услуг

Как любая динамичная экономическая система, рынок государственных услуг нуждается в постоянном развитии и совершенствовании. К числу основных направлений такого развития можно отнести:

Разработка новых продуктов. В секторе государственных услуг процесс разработки новых продуктов формально осуществляется в рамках демократического процесса, когда политики выдвигают некие новые идеи, которые являются ответом либо на новые потребности в повышении эффективности управления, либо на растущие запросы общества. Затем эти идеи проходят апробацию в законодательной и исполнительной ветвях власти, где трансформируются в законодательные акты и нормативные документы, а затем передаются на для исполнения государственным чиновникам. Очень большие области государственного сектора услуг, обслуживающих потребности населения, берут свое начало в подобном партийно-политическом процессе [9].

Однако такая формальная модель ограничена тем, что не дает полного представления о 
роли государственных служащих в разработке продукта. В частности, профессиональные государственные служащие-специалисты могут рассматриваться в качестве важного источника новых продуктов, несмотря на их конституционно и формально подчиненное положение. Такие специалисты в силу накопленного ими опыта и подготовки к деятельности в определенных сферах обеспечения государственных услуг, являются основным источником идей о том, какие новые формы предоставления государственных услуг следует или не следует предлагать общественности. Иногда они могут информировать политиков и других лидеров общественного мнения о необходимости нового продукта, полагая, что его внедрение будет облегчено за счет принятия этой идеи официальными политическими деятелями.

Совершенствование системы оплаты государственных услуг. Характеристики процесса предоставления услуг государственного сектора включают полный набор видов оплаты и вознаграждения. В некоторых случаях услуги могут быть доступны бесплатно в государственном секторе, в то время как в других местах эти же услуги предоставляются частным образом по рыночным ценам. Оплата услуг в этих случаях обычно пропорциональна использованию. С другой стороны, большое количество общественных услуг являются общественными благами и бесплатны в момент предоставления.

Наиболее сложными являются те услуги, оплата которых производится путем налогообложения при наличии рыночных альтернатив. Это категория, относительно которой чаще всего выдвигаются обвинения в неэффективном нормировании. Так, например, медицинские и социальные услуги часто предполагают значительное перекрестное субсидирование, в результате которого относительно финансово обеспеченные граждане частично оплачивают услуги, потребляемые малообеспеченными. Многие участники финансирования услуг редко используют их напрямую и могут считать себя ущемленными. Сопротивление потребителей может проявляться непосредственно в удержании платежа или голосовании за партии, которые обещают низкие налоги и/или низкие отчисления. Неспособность убедить средний класс в выгоде того, что, по сути, является трансфертом дохода, может привести либо к более широкому использованию альтернатив частного сектора, либо к снижению готовности платить, либо к тому и другому.

Совершенствование процесса предоставления услуг. Многие из государственных услуг предоставляются организациями как государственного, так и частного секторов множеством способов. В одних случаях между ними существует жесткая конкуренция на рынке, в других та или иная организация имеет монополию. В прошлом государственный сектор традиционно предоставлял общественные услуги через механизмы государственных ведомств, жилищных органов, медицинских комиссий и т.д. В настоящее время наблюдается тенденция к заключению контрактов на предоставление услуг с внешними агентствами.

Основным новшеством, изменившим характер процессов в государственном секторе, является создание так называемых «внутренних рынков». Эти внутренние рынки не являются реальными рынками - они надуманы. Переход от сотрудничества и коллегиальности к конкуренции и заключению договоров призвана воспроизводить конкурентные условия частного сектора. По крайней мере, вначале на новых внутренних рынках одни и те же люди выполняют одну и ту же работу. Изменения проявляются в том, что информационные ресурсы, которые раньше были открыты, становятся недоступными для коллег, которые теперь играют роль конкурентов.

Совершенствование системы оценки масштабов деятельности и результатов. Организационный контроль представляет особые проблемы в общественных и некоммерческих организациях. Они проистекают из трудностей в достижении консенсуса по целям, которые остаются в значительной мере неопределенными, измерения результатов и убеждения граждан проявлять интерес к показателям эффективности работы государственных структур. Основная проблема заключается в том, что финансовые и количественные показатели не указывают на успех в организациях государственного сектора - необходимо также учитывать качественные показатели.

Большая часть управления в государственном секторе направлена на управление взаимозависимостями: недостаток в одной области приводит к проблемам в другой. Множественные, нефинансовые, противоречивые цели делают процесс оценки эффективности особенно 
трудны. В последнее время принято в большой степени полагаться на косвенные показатели результативности, особенно на те, которые измеряют эффективность, действенность и справедливость. Службы государственного сектора все еще должны решать проблему нематериальных выгод. Подразумевается, что общественность должна быть уверена в том, что организации государственного сектора обеспечивают оптимальное соотношение цены и качества [3].

Вместе с тем, следует акцентировать внимание на том, что дальнейшее совершенствование сектора государственных услуг в странах со сме- шанной экономикой требует обеспечения ответственности органов государственной власти за их качественное предоставление и создание условий для реализации физическими и юридическими лицами своих прав и законных интересов. Получатели услуг должны быть уверены в том, что индивидуальные административные акты являются основанием для осуществления соответствующих законных действий, а в случае нарушения прав получателей услуг, органы государственной власти будут нести за это ответственность.

\section{Библиографический список}

1. Батырева Д. Б. Повышение качества и доступности предоставления государственных и муниципальных услуг как приоритетное направление государственного управления Российской Федерации // Экономика и предпринимательство. 2019. № 7 (108). С. 93-97.

2. Зуева С.М., Осипова М.Ю.Инструментарий стратегического управления клиентоориентированным центром по оказанию государственных услуг // Там же. 2019. № 10 (111). С. 1063-1069.

3. Погодина И.В.Факторы, оказывающие негативное влияние на качество государственных услуг, Государственная власть и местное самоуправление. 2018. № 6. С. 23-25.

4. Потебня Н.В.Сущность системы управления государственными услугами // Colloquium-journal. 2019. № 26-9(50). С. 207-208.

5. Сидоренко Э.Л.Эффективность цифрового государственного управления: теоретические и прикладные аспекты // Вопросы государственного и муниципального управления. 2019. № 2. С. 93-114.

6. Челелева Н.А. Системный подход к управлению учреждениями здравоохранения // Инновации и инвестиции. 2019

7. Alford, J. Defining the client in the public sector: A social-exchange perspective. // Public Administration Review, 2002, Vol. 62(3), pp. 337-346.

8. Andaleeb, S. S., Huda, S. S., Akhtar, A., \& Dilshad, S. Customer satisfaction with complaint resolution in the power sector in a developing economy. // Journal of Nonprofit \& Public Sector Marketing, 2012, Vol. 24(3), pp. 181-201.

9. Graham, P. Marketing in the public sector: Inappropriate or merely difficult? // Journal of Marketing Management, 1994, Vol. 10(5), pp. 361-375.

10. Kelly, J.M. The dilemma of the unsatisfied customer in a market model of public administration. // Public Administration Review, 2005, Vol. 65(1), pp. 76-84.

11. Laing, A. Marketing in the public sector: Towards a typology of public services. // Marketing Theory, 2003, Vol. 3(4), pp. $427-445$.

12. McFadyen, K., Harrison, J. L., Kelly, S. J., \& Scott, D.Measuring service quality in a corporatised public sector environment. // Journal of Nonprofit \& Public Sector Marketing, 2001, Vol. 9(3), pp. 35-51. 